\title{
Effect of speed of muscle contraction on physiological tremor in normal subjects and in patients with thyrotoxicosis and myxoedema ${ }^{1}$
}

\author{
C. D. MARSDEN ${ }^{2}$, J. C. MEADOWS 3 , AND G. W. LANGE4 \\ From the Departments of Medicine and Neurology, St. Thomas's Hospital, London S.E.1, and the National \\ Physical Laboratory, Teddington
}

SUMMARY The speed of the ankle jerk and physiological finger tremor in patients with thyrotoxicosis and myxoedema have been compared with those in age-matched control subjects. Tremor amplitude depends on the speed of muscle contraction; the faster muscle contracts the greater is the amplitude of tremor, and vice versa. The frequency of the dominant tremor peak is not affected by the speed of contraction but its size increases as muscle contracts faster. Muscle dynamics is clearly one of many factors influencing physiological tremor but is not responsible for the dominant frequency of tremor at round $9 \mathrm{c} / \mathrm{sec}$.

We are aware that our hands shake when we try to keep them still, but we do not know why. Although some writers, notably Marshall and Walsh (1956), have suggested that this physiological tremor is due to muscle acting as a 'low pass filter', there have been no systematic studies on the effect of changes in muscle dynamics on tremor. The changes in speed of muscle contraction that occur in thyroid disease provide an excellent opportunity for such a study; we report here the characteristics of tremor of the outstretched finger in patients with hyper- and hypothyroidism, when compared with normal subjects, with particular reference to the correlation of tremor with speed of muscle contraction. Tremor amplitude is shown to depend on muscle dynamics; the faster the muscle contracts the greater is the amplitude of tremor. In contrast, the frequency of the well-known $9 \mathrm{c} / \mathrm{sec}$ peak in the frequency spectrum of physiological tremor, which has attracted great attention as a possible indication of oscillation in some neuronal circuit, is shown to be relatively independent of changes in muscle speed. Peak size, however, does appear to increase as muscle contracts faster.

This work was supported by the National Fund for Research into Crippling Diseases, and also by a grant from the Central Research Fund of London University.

'Present address: Institute of Psychiatry, De Crespigny Park, Denmark Hill, London S.E.5.

3Present address: The National Hospital for Nervous Diseases, Queen Square, London W.C.1.

Present address: Centre for Computing and Automation, Imperial College, London.
METHODS

Tremor of the outstretched finger was studied in nine hyperthyroid and 12 hypothyroid patients who volun teered for the investigations. Thyroid status was estab lished by radioactive iodine studies and where necessar by estimation of serum protein bound iodine. Eight of the hyperthyroid and seven of the hypothyroid patients were restudied five to 26 weeks after starting treatment? although they were not necessarily fully euthyroid by this stage. Treatment of the hyperthyroid patients was either by oral administration of carbimazole or by thyroid ablation with radioactive iodine $\left({ }^{131}\right)$; treatment of the hypothyroid patients was with oral thyroxine. The results obtained in the patients were compared with those from 21 age-matched normal subjects who were either colleagues or volunteer patients in hospital for minor surgery or investigation of unrelated diseases. Only one of the subjects studied (a patient with myxoedema who is discussed in detail later) had evidence of neurological disease.

Tremor of the outstretched index finger was recorded by an-accelerometer (Ether BLA2, weight $2 \cdot 25 \mathrm{~g}$ ) strapped over the dorsal surface of the terminal interphalangeal joint. The subject's pronated right forearm rested on a rigid surface supported up to the wrist. During each period of tremor recording the subject extended the wrist and fingers so that they were in line with the forearm and held this position without visual reference for a period of $2 \mathrm{~min}$. The accelerometer detected fluctuations of the position of the outstretched index finger. The output of the accelerometer was amplified and passed through a filter acting as an integrator above $1 \mathrm{c} / \mathrm{sec}$ so as to obtain a signal corresponding to the velocity of finger movement. 
This was fed to an analogue-to-digital converter to obtain punched paper tape (at 110 characters per second) for subsequent computer analysis, details of which have been presented elsewhere (Marsden, Meadows, Lange, and Watson, 1969a). The frequency spectrum of the recorded finger tremor between 1 and $20 \mathrm{c} / \mathrm{sec}$ was computed as the power spectral density in $(\mathrm{mm} / \mathrm{sec})^{2}$ per $\mathrm{c} / \mathrm{sec}$ at 0.5 $\mathrm{c} / \mathrm{sec}$ intervals. Tremor amplitude between 1 and $20 \mathrm{c} / \mathrm{sec}$ was expressed as root mean square (r.m.s.) error velocity in $\mathrm{mm} / \mathrm{sec}$; tremor amplitude thus refers to the mean velocity of finger movement, not to the mean finger displacement. Tremor spectra (see Fig. 2) were plotted as power spectral density in $(\mathrm{mm} / \mathrm{sec})^{2}$ per $\mathrm{c} / \mathrm{sec}$ on a logarithmic scale against frequency $(\mathrm{c} / \mathrm{sec})$. Such spectra usually show a dominant peak, and the size of this peak relative to tremor at other frequencies between 1 and $20 \mathrm{c} / \mathrm{sec}$ was expressed as the percentage of the total error velocity between 1 and $20 \mathrm{c} / \mathrm{sec}$ in the 0.5 cycle band at peak frequency. Peak frequency itself was expressed to the nearest half-cycle.

The calf muscle twitch evoked by a tap to the Achilles tendon was recorded photo-electrically by the method described by Gilson (1959). The duration of the evoked twitch was measured as the time from onset of tap artefact to the point of half-relaxation. The time from onset of tap artefact to onset of muscle contraction represents the time taken for the evoked spindle discharge to traverse the monosynaptic reflex arc (approximately $40 \mathrm{msec}$ ). It is not altered in thyroid disease (Lawson, 1958) nor does it vary significantly at different ages (Appenzeller, Imarisio, and Gilbert, 1966); accordingly $40 \mathrm{msec}$ was subtracted from each measurement to give a more accurate value for the time from onset of muscle contraction to half-relaxation $\left(\mathrm{T} \frac{1}{2}\right.$ in $\left.\mathrm{msec}\right)$; this could not be measured directly for the moment at which contraction started was difficult to define.

Variation in the amplitude of the evoked muscle twitch does not alter $\mathrm{T} \frac{1}{2}$ markedly, but the force of the tendon tap was adjusted to give twitches of roughly comparable amplitude in all subjects. To avoid possible 'warm-up artefact' (Simpson, Blair, and Nartowicz, 1963) records for measurement were taken after at least six preliminary responses. Mean $\mathrm{T} \frac{1}{2}$ was calculated from at least five responses, which were recorded immediately after the tremor was measured.

Statistical analysis of the results was by Student's test of differences between means using a two-tailed test of significance.

\section{RESULTS}

SPEED OF CALF TWITCH As was expected, T $\frac{1}{2}$ of the calf twitch was shorter than normal in hyperthyroid patients and longer than normal in hypothyroid patients. After treatment $T_{\frac{1}{2}}$ returned to normal values in both groups (Fig. 1).

TREMOR SPECTRUM The shape of the tremor spectrum varied in different subjects; for this reason it was not possible to present the data in the form of mean spectral shapes. Each individual spectrum is therefore shown in Fig. 2. There are obvious differences between the tremor spectra of hypothyroid and hyperthyroid subjects; Table 1 summarizes these differences.

TREMOR AMPLITUDE In general, the amplitude of tremor (expressed as r.m.s. error velocity between 1 and $20 \mathrm{c} / \mathrm{sec}$ ) was inversely related to the duration of the calf twitch; tremor amplitude fell as $T_{\frac{1}{2}}$ increased (Fig. 3). The most severely affected hypothyroid patient (M1) was an obvious exception, but this patient showed features of the myxoedematous cerebellar syndrome that may complicate hypothyroidism (Jellinek and Kelly, 1960) and developed a marked tremor when attempting to maintain a steady posture. She is therefore excluded from the mean figures given in Table I but appears (arrowed) in Fig. 3. When this patient is excluded, there was a highly significant correlation between tremor amplitude and $T_{\frac{1}{2}}$ in the hyperthyroid, normal and hypothyroid groups $(\mathrm{n}=40 ; \mathrm{r}=0.83 ; P<0.001)$.

After treatment $T \frac{1}{2}$ and tremor amplitude returned towards normal (Fig. 1 and Fig. 4). Tremor amplitude decreased while $T \frac{1}{2}$ increased in all eight hyperthyroid patients, and tremor amplitude increased while $\mathrm{T} \frac{1}{2}$ decreased in six of the seven hypothyroid patients. Tremor amplitude thus changed inversely to the change in $T \frac{1}{2}$ in 14 of the 15 patients studied after treatment.

PEAK FREQUENCY All the normal subjects and all the hyperthyroid patients had a well-defined dominant peak in the tremor spectrum at about 7 to $11 \mathrm{c} / \mathrm{s}$. However, only eight of the 12 hypothyroid patients had a single dominant tremor peak and this was generally smaller and less prominent than in the normal or hyperthyroid subjects (Fig. 2). The tremor spectrum in the remaining four hypothyroid patients (M4, M5, M8, M9) had two or more peaks; each of these four subjects had a small peak between 8 and $10 \frac{1}{2} \mathrm{c} / \mathrm{sec}$, and a second slightly larger peak between 5 and $6.5 \mathrm{c} / \mathrm{sec}$. Three of the eight hypothyroid patients with larger peaks between 7 and $11 \mathrm{c} / \mathrm{sec}$ also had a small peak around $5 \mathrm{c} / \mathrm{sec}$. For the purposes of comparison with the hyperthyroid and normal groups only those eight hypothyroid patients with a dominant peak between 7 and $11 \mathrm{c} / \mathrm{sec}$ have been considered; the significance of the low frequency peak will be discussed later.

The mean peak frequency for both the hyperthyroid and hypothyroid patients was slightly lower than that of their age-matched controls but these differences were not statistically significant (Table 1 and Fig. 5), and there was no significant correlation 


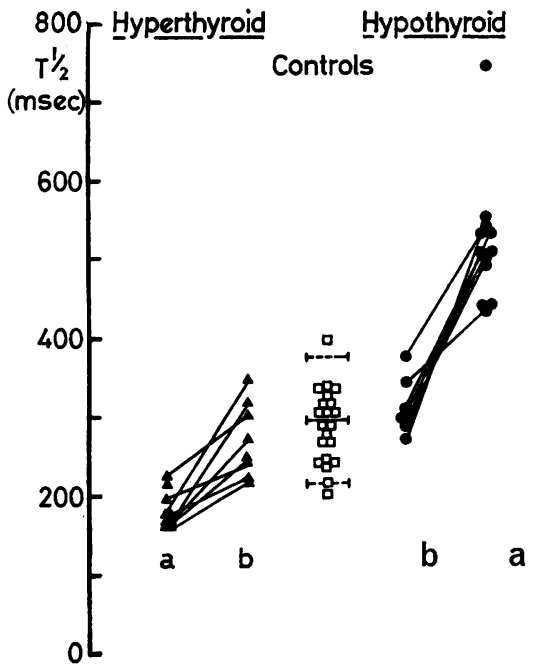

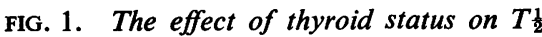
in the patients studied. Hyper- and hypothyroid patients are shown before (a) and after (b) treatment and are compared with the age-matched controls. The continuous and interrupted lines in the control column represent the mean and 2 standard deviations of a much larger series of normal subjects studied by the same technique.
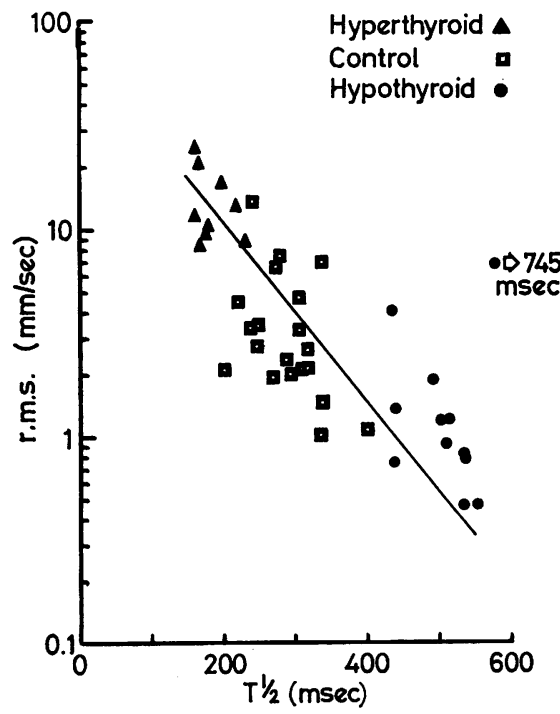

FIG. 3. The relationship between total r.m.s. velocity and $T \frac{1}{2}$ in the hyperthyroid and hypothyroid patients, and their control subjects. The calculated regression line does not include patient M1 (arrowed). $T_{\frac{1}{2}}=$ 655.6 - 224.4 Log r.m.s., $r=0.83, P<$ 0.001 .

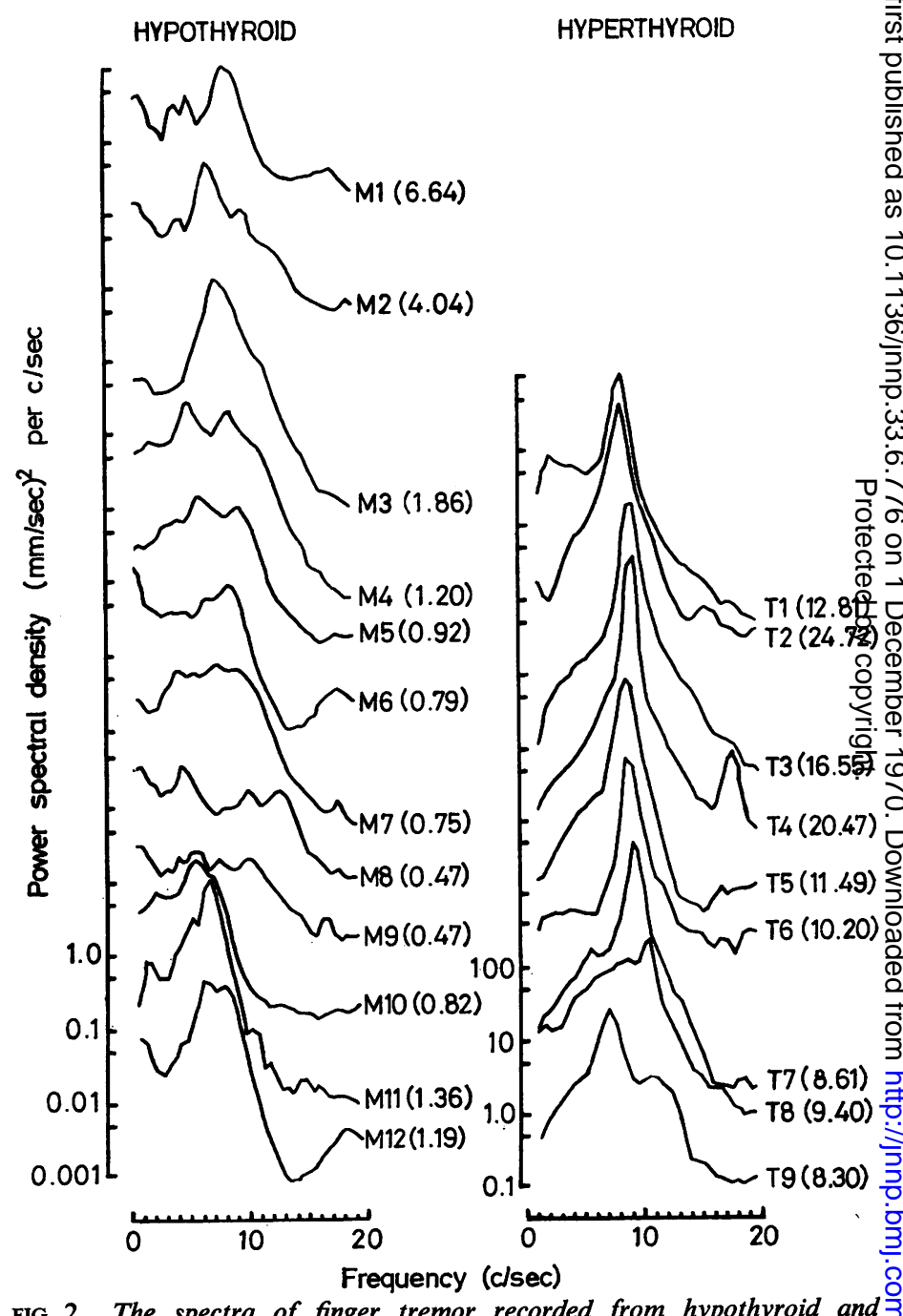

FIG. 2. The spectra of finger tremor recorded from hypothyroid and hyperthyroid subjects. The values for power spectral density shown on the ordinates refer to the bottom spectrum (M12 and T9 respectively) in each 5 composite graph. To aid presentation the spectra for M11 and T8 are dis- $\rightarrow$ placed upwards by 1 log unit, those for M10 and T7 by a further log unit and so on. The figures given in brackets are the r.m.s. values $(\mathrm{mm} / \mathrm{sec})$ for each $\mathrm{N}$ spectrum. 
TABLE 1

MEAN VALUES (WITH STANDARD DEVIATION) FOR T $\frac{1}{2}$, TREMOR AMPLITUDE, PEAK FREQUENCY, AND RELATIVE PEAK SIZE IN PATIENTS WITH THYROID DISEASE COMPARED WITH AGE-MATCHED CONTROLS

\begin{tabular}{|c|c|c|c|c|c|c|}
\hline & Hypothyroid & Normals & $\begin{array}{l}\text { Significance of } \\
\text { difference }\end{array}$ & Hyperthyroid & Normals & $\begin{array}{c}\text { Significance of } \\
\text { difference }\end{array}$ \\
\hline $\begin{array}{l}\text { Age } \\
\text { (range) }\end{array}$ & $\begin{array}{c}56 \\
(37-82)\end{array}$ & & & $\begin{array}{c}44 \\
(21-64)\end{array}$ & & \\
\hline $\begin{array}{l}\mathrm{T} \frac{1}{2} \\
(\mathrm{msec})\end{array}$ & $\begin{array}{c}n=11^{*} \\
499 \pm 43\end{array}$ & $\begin{array}{c}n=11^{*} \\
295 \pm 33\end{array}$ & $P<0.001$ & $\begin{array}{c}n=9 \\
182 \pm 25\end{array}$ & $\begin{array}{c}n=9 \\
276 \pm 62\end{array}$ & $P<0.01$ \\
\hline $\begin{array}{l}\text { Tremor amplitude } \\
\text { (r.m.s. between } 1 \text { to } 20 \mathrm{c} / \mathrm{sec} \text { in } \mathrm{mm} / \mathrm{sec} \text { ) }\end{array}$ & $\begin{array}{c}n=11^{*} \\
1 \cdot 26 \pm 1 \cdot 01\end{array}$ & $\begin{array}{c}n=11^{*} \\
3.91 \pm 3.58\end{array}$ & $P<0.02$ & $\begin{array}{c}n=9 \\
13 \cdot 62 \pm 5 \cdot 77\end{array}$ & $\begin{array}{c}n=9 \\
3 \cdot 56 \pm 2 \cdot 27\end{array}$ & $P<0.001$ \\
\hline $\begin{array}{l}\text { Peak frequency } \\
(\mathrm{c} / \mathrm{sec})\end{array}$ & $\begin{array}{c}\mathbf{n}=8 \dagger \\
7 \cdot 5 \pm 1 \cdot 0\end{array}$ & $\begin{array}{c}n=8 \dagger \\
8 \cdot 4 \pm 1 \cdot 1\end{array}$ & NS & $\begin{array}{c}n=9 \\
8 \cdot 6 \pm 1 \cdot 0\end{array}$ & $\begin{array}{c}n=9 \\
9 \cdot 1 \pm 1 \cdot 4\end{array}$ & NS \\
\hline $\begin{array}{l}\text { Relative peak size } \\
\text { (\% of tremor at peak frequency) }\end{array}$ & $\begin{array}{c}n=8 \dagger \\
14 \cdot 2 \pm 6 \cdot 0\end{array}$ & $\begin{array}{c}n=8 \dagger \\
23.9 \pm 14.8\end{array}$ & NS & $\begin{array}{c}n=9 \\
32 \cdot 4 \pm 10 \cdot 3\end{array}$ & $\begin{array}{c}n=9 \\
21 \cdot 7 \pm 11 \cdot 8\end{array}$ & NS \\
\hline
\end{tabular}

*The hypothyroid patient with features of the myxoedematous cerebellar syndrome is excluded from the mean figures shown.

$\dagger$ The four patients without dominant tremor peaks are excluded (see text).

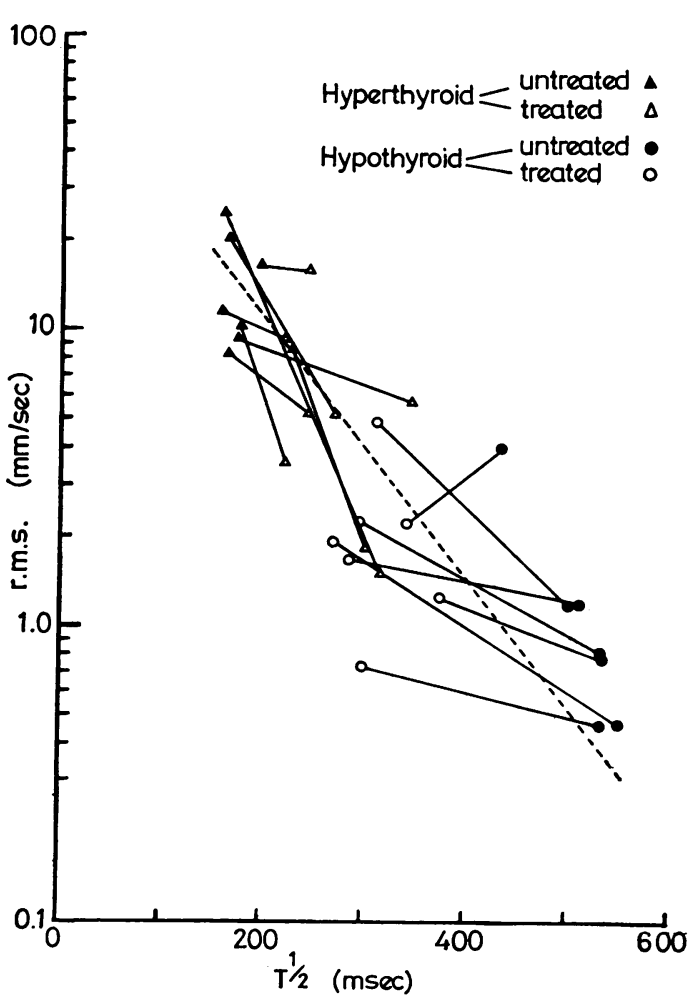

FIG. 4. The relationship between total r.m.s. velocity and $T \frac{1}{2}$, showing the effect of treatment in the eight hyperthyroid and seven hypothyroid patients in whom records were obtained before and after treatment. The two points for each patient are linked by continuous lines. The interrupted line is the regression calculated in Fig. 3.

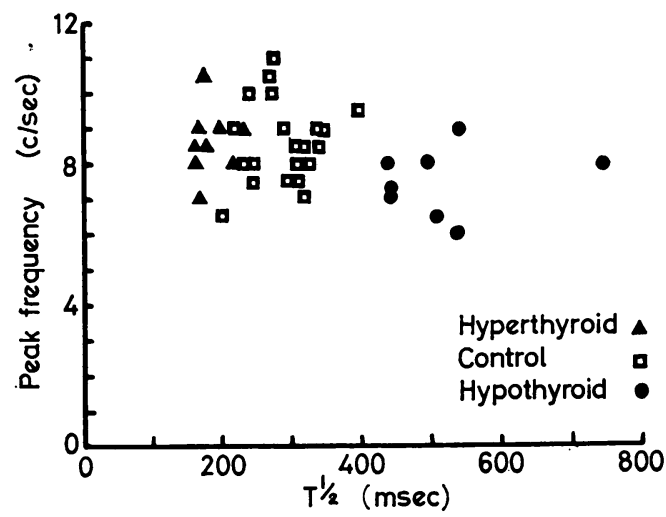

FIG. 5. The relationship between frequency of tremor peak and $T_{\frac{1}{2}}$ in hyperthyroid and hypothyroid patients and their control subjects.

between peak frequency and the duration of the calf twitch.

After treatment, peak frequency did not alter significantly in the hyperthyroid patients (it was unchanged in three, fell by up to $1.5 \mathrm{c} / \mathrm{sec}$ in three and rose by up to $1 \mathrm{c} / \mathrm{sec}$ in three); in the hypothyroid patients, peak frequency rose by up to $3 \mathrm{c} / \mathrm{sec}$ in all four subjects studied after treatment.

RELATIVE SIZE OF TREMOR PEAK The relative size of the dominant tremor peak (percentage of power in the half cycle band at peak frequency) was significantly smaller in the hypothyroid than the hyperthyroid patients $(P<0.001)$. Both control groups gave intermediate figures but the difference from the 
patient groups was not statistically significant (Table 1).

In a large series of 58 normal subjects, we have found that peak size bears a direct relationship to overall tremor amplitude (Marsden et al., 1969a) and it was our impression that a similar relationship existed in the present patients, although this was not proven by paired $t$-testing against controls. Figure 6 shows the regression line (with $50 \%$ confidence limits) of the relationship between peak size and tremor amplitude in the large control series. Superimposed are the data for the hypo- and hyperthyroid patients under discussion. It can be seen that these fall mainly at opposite ends of the regression line, suggesting a direct relationship between the two variables. Other factors distinguishing these two groups, such as mean age and mean peak frequency (see Table 1) are unlikely to be responsible, for these had no influence on peak size in the control series (unpublished observations).

After treatment, the peak size increased in all four hypothyroid patients but decreased in only five of the eight hyperthyroid patients that were restudied.

\section{DISCUSSION}

It is generally believed that physiological tremor is caused by a tendency for some motor units to synchronize their firing rates at around $10 \mathrm{c} / \mathrm{s}$. Lippold and his colleagues (Lippold, Redfearn, and Vučo, 1957) were able to demonstrate such group-

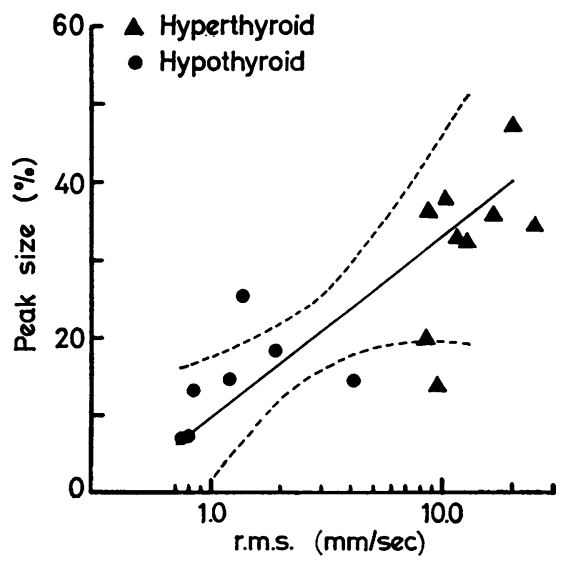

FIG. 6. The relationship between relative size of tremor peak and total r.m.s. velocity in the hyperthyroid and hypothyroid patients. The regression (continuous line) and $50 \%$ confidence limits (interrupted lines) are calculated from a large series of 58 normal subjects.

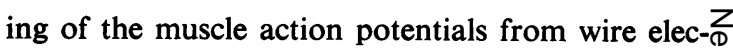
trodes inserted into the calf muscles of the standing subject, and to show that such burst of electro-es myographic activity coincided with the mechanicale oscillations of tremor recorded from the ball of the foot (their Fig. 4). They were able to record such? rhythmic electromyographic activity from a variety? of other muscles in the arm and leg. However, Marshall, and Walsh (1956) were unable to demon-: strate synchronization of motor unit activity in $\overrightarrow{\mathrm{G}}$ electromyograms recorded with surface electrodes and, therefore, put forward an alternative hypothesis to explain physiological tremor. They observed that $\frac{\bar{c}}{\bar{D}}$ when the motor nerve to a muscle is repetitively $\vec{\Phi}$ stimulated, 'a rate of discharge below about $15 \mathrm{c} / \mathrm{sec}$ 을 in the motor fibres is converted into mechanical कs ripples by the muscles, but higher rates of neural dis- $\vec{\circ}$ charges are blocked or filtered by the physical con- $\vec{A}$ stitution of the muscle'. They therefore suggested $\vec{\omega}$ that muscle acted as a low pass filter preventing? oscillation of muscle force when motor nerve discharge frequencies exceeded about $15 / \mathrm{sec}$, but $\dot{\omega}$ allowing oscillation (as in an unfused tetanus) when stimulated at lower frequencies. Such an explanation would indeed accord with the negligible tremor oे power seen at frequencies above about $15 \mathrm{c} / \mathrm{sec}$ 荫응 the tremor spectra shown in Fig. 2, but fails tr. explain the dominant peak at about $10 \mathrm{c} / \mathrm{sec}$; the slower the frequency of muscle stimulation the greater is the oscillation in an infused tetanus, 50 that tremor should be even more marked at frequencies below that of the observed peak. Accors ingly, it is still necessary to assume a tendency for motor units to fire at about $10 \mathrm{c} / \mathrm{sec}$, as Lippold. et al. observed, to explain the shape of the tremor spectrum.

The present paper demonstrates the importance of the filtering properties of muscle, not in determining the frequency of tremor, but in influencing $\mathbb{Q}$ its amplitude. The striking relationship between $\overrightarrow{\vec{D}}$ tremor amplitude and speed of muscle contraction observed in this study is explicable in terms of the effect of changes of muscle speed on the degree of oscillation in the force produced by the tendency for motor units to fire at about $10 / \mathrm{sec}$. The amplitude of this oscillation will depend not only upon the number of synchronously firing motor units but also on the speed of the muscle response; the faster the muscle contracts the greater will be the oscillation and vice versa (see Fig. 7). Other conditions known to alter the speed of muscle contraction also alter the amplitude of tremor $\frac{D}{2}$ appropriately. Cooling the limb (Marshall and Walsh, 1956; Lippold et al., 1957) and ischaemia No (Halliday and Redfearn, 1954) both slow twitch speed and reduce tremor amplitude, while adrenaline 
T8
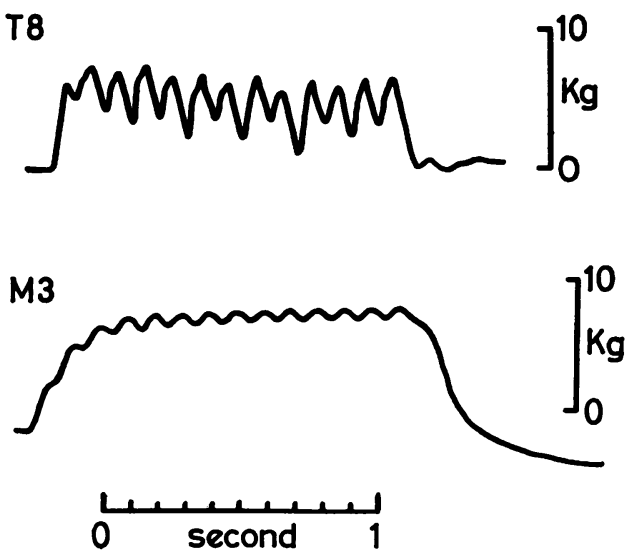

FIG. 7. Tension recorded isometrically with the foot strapped to footplate incorporating a strain gauge in a hyperthyroid subject (T8) and a hypothyroid subject (M3) during 10/sec tetanic stimulation of the medial popliteal nerve. The oscillation in tension produced by the calf muscles is strikingly larger in the hyperthyroid subject.

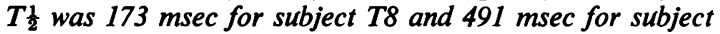
M3.

increases twitch speed and tremor (Marsden and Meadows, 1970), even in the deafferented limb (Marsden, Meadows, Lange, and Watson, 1967).

Our observations on tremor in hypothyroid patients also indicate that the shape of the tremor spectrum alters when muscle contracts very slowly. The peak at about $9 \mathrm{c} / \mathrm{sec}$ which dominates the spectrum in normal and thyrotoxic subjects becomes very much smaller and other peaks become apparent particularly at about $5 \mathrm{c} / \mathrm{sec}$ (see Fig. 2). However, even in those subjects with a very large peak at the low frequency there is also a small peak at about $9 \mathrm{c} / \mathrm{sec}$. It is notable that the subjects with multiple peaks in the tremor spectrum are those with the lowest amplitude of tremor and that the shape of their tremor spectra is very similar to that of the ballistocardiac oscillations that can be recorded from the relaxed finger tip (see Marsden, Meadows, Lange, and Watson, 1969b). In the normal subject, we have concluded that ballistocardiac oscillations account for about $10 \%$ of the tremor recorded from the outstretched finger tip by our standard technique. It is likely that the very slowly contracting muscle of the hypothyroid patient attenuates tremor due to synchronized nervous input and that the contribution of ballistocardiac oscillations is correspondingly increased. Indeed, the power spectrum of the oscillations recorded from the outstretched finger tip of the hypothyroid patient can be remarkably similar to that recorded from the relaxed finger tip (Fig. 8). The spectra illustrated are those showing this similarity most strikingly, but similar results were obtained in three other hypothyroid patients in whom tremor and ballistocardiac oscillations were recorded. The conclusion is that as tremor due to nervous input is attenuated by slowing of muscle contraction, the power spectrum of oscillations recorded from the outstretched finger tip becomes increasingly dominated by the ballistocardiogram. We have seen the same changes in spectral shape occur during cooling of the limb in ice water; the dominant $9 \mathrm{c} / \mathrm{sec}$ peak is replaced by multiple peaks at lower frequencies as tremor amplitude falls.

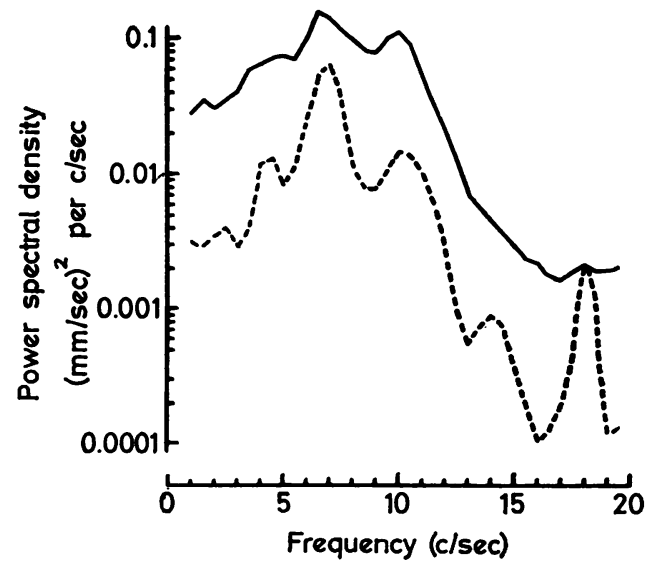

FIG. 8. Frequency spectrum of tremor of the extended index finger (continuous line) and of the oscillations recorded from the relaxed finger tip (interrupted line) in subject M5.

The relative size of the tremor peak differs markedly between hypothyroid and hyperthyroid patients. In general, it seems that the greater the amplitude of tremor the greater is the relative size of the tremor peak (see Marsden et al., 1969a). One suggestion to explain this observation is that increasing mechanical oscillation provides an increasing stimulus to the muscle spindles, whose output tends to synchronize motoneurone discharge around peak frequency. The delay inherent in the operation of the stretch reflex arc (due to delay in nervous impulses reaching the spinal cord and then the muscle itself) has been suggested as the cause of the $10 \mathrm{c} / \mathrm{sec}$ oscillation of motoneurone discharge responsible for physiological tremor (Halliday and Redfearn, 1956; Hammond, Merton, and Sutton, 1956; Lippold et al., 1957), although there is now 
strong evidence against it as the sole mechanism (Marsden et al., 1967). However, Lippold has recently shown that the stretch reflex arc generates a $10 \mathrm{c} / \mathrm{sec}$ train of mechanical oscillations when the finger is suddenly flexed by a prod (Lippold, 1969). The stretch reflex mechanism thus has a tendency to cause motoneurones to fire at about $10 \mathrm{c} / \mathrm{sec}$, and the extent of this tendency will depend upon the size of the spindle output. The increased mechanical oscillation that occurs when tremor is marked acts as a more effective spindle stimulus, and it is possible that the increasing prominence of the $10 \mathrm{c} / \mathrm{sec}$ peak as tremor amplitude increases is the result of greater spindle feedback.

The data presented in this paper fail to show any consistent relation between the speed of muscle contraction and the frequency of the dominant tremor peak. Since the peak frequency of physiological tremor is independent of the dynamics of muscle, and a tremor peak persists after deafferentiation of the limb (Marsden et al., 1967), we must look to the spinal cord or even higher for its source.

We would like to thank the Director of the National Physical Laboratory and Mr. P. Hammond for their hospitality in allowing us the use of the Hermes computer on which these studies were carried out.

\section{REFERENCES}

Appenzeller, O., Imarisio, J. J., and Gilbert, J. J. (1966). The effect of age and neurological disease on the ankle jerk. Arch. Neurol. (Chic.), 15, 147-150.
Gilson, W. E. (1959). Achilles-reflex recording with a simple photomotograph. New Engl. J. Med., 260, 1027-1031.

Halliday, A. M., and Redfearn, J. W. T. (1954). The effect of ischaemia on finger tremor. J. Physiol. (Lond.), 123, 23P-24P.

Halliday, A. M., and Redfearn, J. W. T. (1956). An analysis of the frequencies of finger tremor in healthy subjectses J. Physiol. (Lond.), 134, 600-611.

Hammond, P. H., Merton, P. A., and Sutton, G. G. (1956)

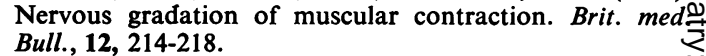

Jellinek, E. H., and Kelly, R. E. (1960). Cerebellar syndrome in myxoedema. Lancet, 2, 225-227.

Lawson, J. D. (1958). The free Achilles reflex in hypothy roidism and hyperthyroidism. New Engl. J. Med., 259 761-764.

Lippold, O. C. J. (1969). Tremor and oscillation in the stretch reflex arc. J. Physiol. (Lond.), 202, 55P-57P.

Lippold, O. C. J., Redfearn, J. W. T., and Vučo, J. (1957) The rhythmical activity of groups of motor units in thes voluntary contraction of muscle. J. Physiol. (Lond.), 137 473-487.

Marsden, C. D., Meadows, J. C., Lange, G. W., and Watson R. S. (1967). Effect of deafferentiation on human physiological tremor. Lancet, 2, 700-702.

Marsden, C. D., Meadows, J. C., Lange, G. W., and Watson R. S. (1969a). Variations in human physiological finger tremor, with particular reference to changes with age $\omega_{\omega}^{\omega}$ Electroenceph. clin. Neurophysiol., 27, 169-178.

Marsden, C. D., Meadows, J. C., Lange, G. W., and Watson; R. S. (1969b). The role of the ballistocardiac impulse In $^{\circ}$ the genesis of physiological tremor. Brain, 92, 647-662

Marsden, C. D., and Meadows, J. C. (1970). The effect官 adrenaline on the contraction of human muscle. J. P siol. (Lond.). (In press.)

Marshall, J., and Walsh, E. G. (1956). Physiological trem\& J. Neurol. Neurosurg. Psychiat., 19, 260-267.

Simpson, G. M., Blair, J. H., and Nartowicz, G. R. (19)्छ్ Diagnostic limitations of Achilles tendon reflex in thyra d. disease. N.Y.S. J. Med., 63, 1148-1153. 